Old Dominion University

ODU Digital Commons

2004

\title{
Age and Growth of Scotia Sea Icefish, Chaenocephalus aceratus, From the South Shetland Islands
}

M. La Mesa

J. Ashford

Old Dominion University, jashford@odu.edu

E. Larson

Old Dominion University

M. Vacchi

Follow this and additional works at: https://digitalcommons.odu.edu/oeas_fac_pubs

Part of the Aquaculture and Fisheries Commons, Environmental Sciences Commons, Marine Biology Commons, and the Oceanography Commons

\section{Original Publication Citation}

La Mesa, M., Ashford, J., Larson, E., \& Vacchi, M. (2004). Age and growth of Scotia sea icefish, Chaenocephalus aceratus, from the south Shetland Islands. Antarctic Science, 16(3), 253-262. doi:10.1017/s0954102004002044

This Article is brought to you for free and open access by the Ocean \& Earth Sciences at ODU Digital Commons. It has been accepted for inclusion in OES Faculty Publications by an authorized administrator of ODU Digital Commons. For more information, please contact digitalcommons@odu.edu. 


\title{
Age and growth of Scotia Sea icefish, Chaenocephalus aceratus, from the South Shetland Islands
}

\author{
M. LA MESA ${ }^{1 *}$, J. ASHFORD ${ }^{2}$, E. LARSON ${ }^{2}$ and M. VACCH ${ }^{3}$ \\ ${ }^{1}$ ISMAR-CNR, Istituto di Scienze Marine, Sezione Pesca Marittima, Largo Fiera della Pesca, 60125, Ancona, Italy \\ ${ }^{2}$ Center of Quantitative Fisheries Ecology, Old Dominion University, Technology Building Room 102, 4608 Hampton Boulevard, Norfolk, \\ VA 23529, USA \\ ${ }^{3}$ Istituto Centrale per la Ricerca Scientifica e Tecnologica Applicata al Mare, Via di Casalotti 300, 00166, Roma, Italy \\ *m.lamesa@ismar.cnr.it
}

\begin{abstract}
Samples of Chaenocephalus aceratus (Lönnberg) were collected during a trawl survey carried out around the South Shetland Islands in January-February 2002. Fish were caught by commercial bottom trawl fishing down to $500 \mathrm{~m}$ depth, using a stratified randomized sampling design. As observed in other recent surveys within the same area, $C$. aceratus represented one of the predominant species. Overall, 357 specimens ranging from 13 and $67 \mathrm{~cm}$ (TL) were selected for the present study. Ages were estimated by counting annuli present in the sagittal otoliths, exposed by grinding and polishing along their sagittal plane. To estimate the precision of age data, we compared blind readings by readers from different institutions. The age range was 1-17 years for females and 1-15 years for males. Von Bertalanffy growth curves were fitted to the estimated age-length data for each sex. The estimated values of asymptotic length $\mathrm{L}_{\infty}(\mathrm{cm})$ and $\mathrm{K}$ (year ${ }^{-1}$ ) were respectively 79.8 and 0.07 for females and 60.0 and 0.09 for males. The growth performance index ranged between 2 and 2.5, similar to that reported in other icefish. Sexual maturity was attained by females and males at about 10 and 9 years old respectively, at about $60 \%$ of their maximum estimated age. These results are compared with age and growth data available in the literature for C. aceratus, and discussed in the light of recent commercial exploitation.
\end{abstract}

\section{Received 18 December 2003, accepted 13 April 2004}

Key words: CCAMLR, growth performance index, otoliths, sexual maturity, Southern Ocean

\section{Introduction}

Fish stocks around the South Shetland Islands and off the tip of the Antarctic Peninsula (FAO Statistical Subarea 48.1) were exploited from 1978/1979 to 1988/89, before the area was closed for finfishing in 1989/1990 (Kock 1992). Since 1996, trawl surveys have been conducted around the South Shetland Islands by RV Yuzhmorgeologiya (US AMLR Surveys, 1998 and 2001) and RV Polarstern (Cruises ANT $\mathrm{XIV} / 2$ and ANT XIX/3, 1996 and 2002), to acquire biological data for monitoring the status of the local fish stocks (Kock \& Stransky 2000, Kock et al. 2000, Jones et al. 2001). The surveys greatly improved knowledge of basic biological features of demersal fish species around the islands, such as distribution, abundance, community structure, feeding and reproduction. Nevertheless, there is little information on age and growth, and data on this topic are urgently required (Kock et al. 2000).

Several techniques have been used to reveal increments in hard structures such as otoliths, scales and bones from the Antarctic fishes (Everson 1980, White 1991). Some studies were conducted within the BIOMASS Programme (Everson 1980, North et al. 1980) and by CCAMLR (Kock 1990). Agreement in age interpretation between different readers was often poor and generally decreased with fish longevity (Kock 1990). In addition, ages were frequently underestimated using scales due to scale resorption (Coggan et al. 1990). As a result, although mainly from scientific studies in which the number of specimens was small, otoliths were considered the best structures to use for age determination (White 1991).

The Scotia Sea icefish, Chaenocephalus aceratus (Lönnberg), is one of the most abundant species of the coastal fish fauna around the South Shetland Islands (Kock \& Stransky 2000), and is distributed throughout the Scotia Arc and in the vicinity of Bouvet Island as deep as $770 \mathrm{~m}$ (Iwami \& Kock 1990). The icefish was caught as bycatch in the trawl fishery mainly around South Georgia, although annual catches around the South Orkney Islands, Elephant Island and lower South Shetland Islands were in the order of several hundred tonnes. However, very little information on age and growth of $C$. aceratus has been reported to date. Age determination by several authors were obtained by means of polymodal length frequency distributions analysis and are only available for juvenile specimens of $C$. aceratus (Kompowski 1980, Kock 1981, Slósarczyk 1987). Age and growth of adult specimens of $C$. aceratus have been studied by Olsen (1955) and Gubsch (1980) from South Georgia, and more recently by Kompowski (1990).

In this paper, we report on the age and growth of C. aceratus around the South Shetland Islands. As icefish 
do not have scales, otoliths were collected from C. aceratus taken during the 2002 Polarstern Cruise (ANT XIX/3) carried out in the CCAMLR Statistical Subarea 48.1. Following the ageing procedure implemented through CCAMLR for toothfish (CCAMLR Otolith Network, CON, Ashford 2002), blind age readings were undertaken at ISMAR-CNR (Istituto di Scienze Marine, Sezione Pesca Marittima) and CQFE (Centre for Quantitative Fisheries Ecology) to compare precision in age data between and within different readers.

\section{Material and methods}

A fisheries survey was carried out during the Polarstern Cruise ANT XIX/3 conducted around the South Shetland Islands (mainly Elephant Island and King George Island) between January and February 2002. Sampling was undertaken using a commercial benthic trawl with a codend mesh size of $40 \mathrm{~mm}$, and using a random stratified survey design. Five depth strata were selected: $0-100 \mathrm{~m}$, 101-200 m, 201-300 m, 301-400 m and 401-500 m. Each haul was carried out for $30 \mathrm{~min}$ at a towing speed of about 3 knots. The fish were sorted from the catches, identified to species level, measured to the nearest lower $\mathrm{cm}$ and weighed (g). Samples of $C$. aceratus were subsampled in the following manner: when less than 50 fish were caught in a haul, all were sampled; otherwise, specimens of length classes with fewer individuals were randomly sampled, in order to cover as much as possible of the maximum length range available.

The maturity of each specimen was recorded using the five point scale of Everson (1977). The length-mass relationship of fish was calculated both for the whole population and for each sex. The exponential equation:

$$
W=a T L^{b}
$$

was fitted to the data, where $\mathrm{W}=$ the total mass $(\mathrm{g}), \mathrm{TL}=$ total length of fish $(\mathrm{cm})$ and $\mathrm{a}$ and $\mathrm{b}$ are regression parameters. By $\log _{10}$-transforming the mass data, the equation was linearized to determine the regression parameters. An F-test was used to test between the allometric indices (b) obtained for males and females (Sokal \& Rohlf 1969).

Sagittal otoliths were removed from the fish, cleaned and stored in vials. The mass of both left and right otoliths (OW) was recorded (with an accuracy of $0.1 \mathrm{mg}$ ) and compared using a $t$-test for paired comparisons (Sokal \& Rohlf 1969), to test for any differences in otolith size (Neilson 1992). As no difference was found ( $\mathrm{df}=346, F=2.93, P>0.05$ ), the maximum lengths $(0.01 \mathrm{~mm})$ of randomly selected otoliths were obtained by means of an image analyser (OPTIMAS software package) linked to a binocular microscope by a CCD video camera. The relationship between fish length (TL) and otolith maximum length (OL) was examined by linear regression analysis (Hecht 1987). Following Everson et al. (1999), the relationship between fish length (TL) and otolith mass (OW, left otolith) was also determined by fitting linear regression to $\log _{10}$-transformed data.

As often observed in Antarctic fish (White 1991), otoliths of $C$. aceratus have a dense calcareous structure and are opaque, so that they had to be sectioned to observe the internal structure. Each right otolith was then embedded in epoxy resin (Implex) and mounted on glass slides. After some trials, the sagittal plane was considered the best sectioning plane, in terms of preparation time and the clarity of growth structures; here annuli were wide enough to be identified easily. Each otolith within the resin block was ground with abrasive paper (800 grit) and polished with alumina powder $(3 \mu \mathrm{m})$ by a grinding wheel (REMET LS2) until the internal structure was evident. As the distal surface of the otolith was convex, the sagittal section was made at a right angle, so that both the core and margin of otoliths were readable.

To improve the image for reading, the slides were fully immersed in water inside a Petri dish and the otolith sections read under reflected light using a stereomicroscope at 25-40x magnification. Sometimes the annulation pattern was not immediately clear, so it was necessary for the sections to soak for a few minutes until the annuli appeared.

\section{Criteria for otolith interpretation}

Under reflected light, the nucleus and the opaque zones appeared as light rings and the translucent (hyaline) zones as dark rings (Everson 1980). The combination of each opaque and subsequent translucent zone from nucleus to otolith margin was considered as one annulus following the definition of Everson (1980) and North (1988). In general, the annuli were quite clear in fish up to ten years of age, but in older fish, the outer annuli were often split in two or more checks, making annuli difficult to identify. In this case, the count path was changed and annuli counted along the antero-ventral axis. Otherwise, the count path was generally from the core towards a postero-dorsal axis.

In $C$. aceratus, hatching is thought to occur in August (Kellerman 1989). Within the nucleus, which contained a clear central core, a series of micro-increments were observed, which were considered to be the first opaque zone laid down in the first summer season after hatching. Assuming the first translucent zone is laid down on the otolith during the following winter, (North 1988), we counted the first translucent zone as the end of Year 1. As the sample was caught in summer (January-February), the last annulus on the otolith margin (often constituted by the opaque zone) was not considered in the count.

Along the count path, the annuli close to the nucleus were wide and slightly decreasing in width toward the otolith margin, with large translucent zones (especially the first two). Moving away from the nucleus, the annuli were narrower than the previous ones, though similar in width to 


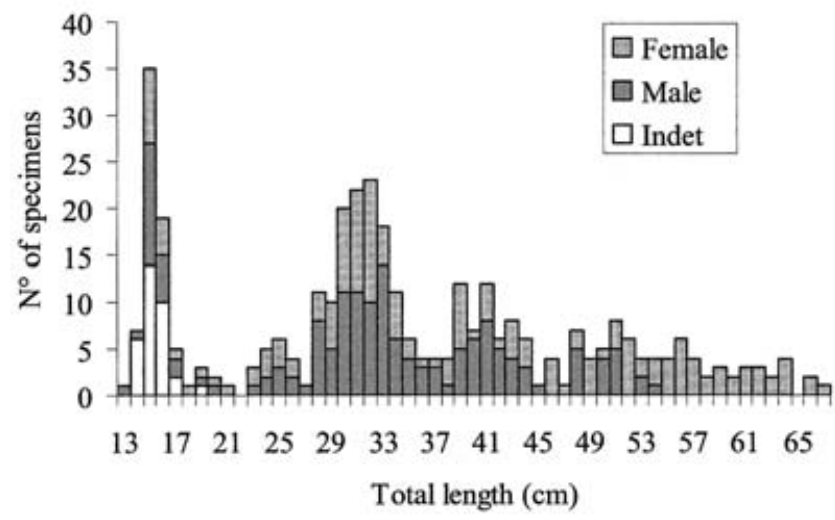

Fig. 1. Length-frequency distribution of Chaenocephalus aceratus from South Shetlands.

each other, and had very thin translucent zones.

All the otolith sections were firstly read by one reader (MLM), without any auxiliary information. A second reading was carried out a week later. The two readings sometimes differed by one or two years. When readings differed more than two years, a third reading was made; if the difference still remained, these otoliths were discarded. As no systematic differences were observed between the two readings (by means of residual plots), the lower value or the mean value was considered if they differed by one $(32 \%)$ or two years $(11 \%)$, respectively. A subsample (77 items) of otoliths was read twice by another reader (EL), in order to estimate the precision of the age readings. The index of average percent error (APE) (Beamish \& Fournier 1981), as well as the mean coefficient of variation (CV) (Chang 1982), were calculated to estimate the relative precision both within and between readers.

The otolith was assessed for presence of an opaque or translucent zone on the margin, although it was not possible to validate the ages using a full marginal increment analysis, as the sampling period only covered two months. Older fish were not considered in this analysis, as their otoliths often showed very narrow annuli close to the margin and it was difficult to determine whether an opaque or translucent zone was on the margin. To test indirectly whether we were identifying the first year correctly, three specimens between 14-16 cm TL were selected from the first mode of the length frequency distribution (Fig. 1), and aged as 1+ fish according to our criteria; microincrements (daily rings) (Fig. 5) were then also counted to see whether the expected number $=365+$ microincrements occurred (Geffen 1992). Counts were made using the image analysis system with the microscope set at magnification 400x.

In order to estimate age at first maturity, all aged specimens were divided according to sex. Age versus proportion of mature fish ( 2 to 5 stage of maturity) were then plotted and fitted to the following logistic equation:

$$
P=1 /\left[1+e^{-(\alpha+\beta A)}\right]
$$

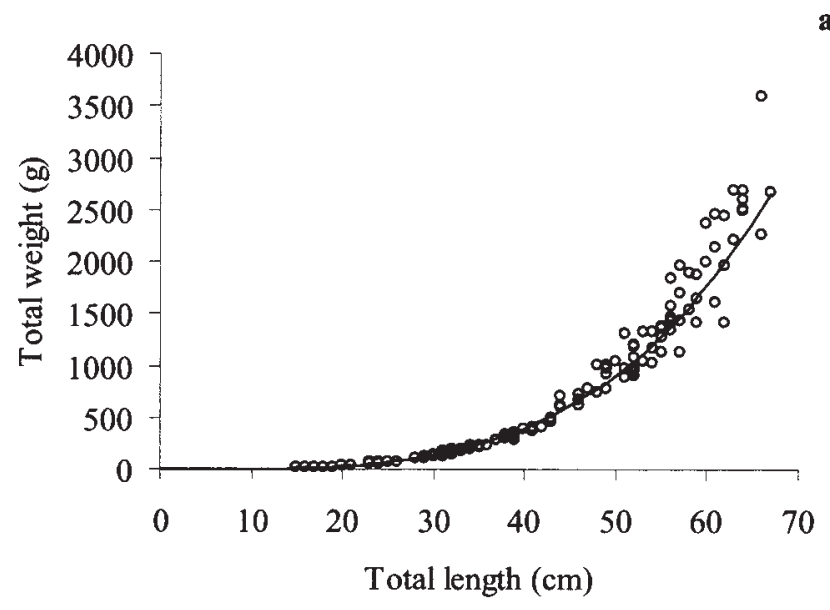

b

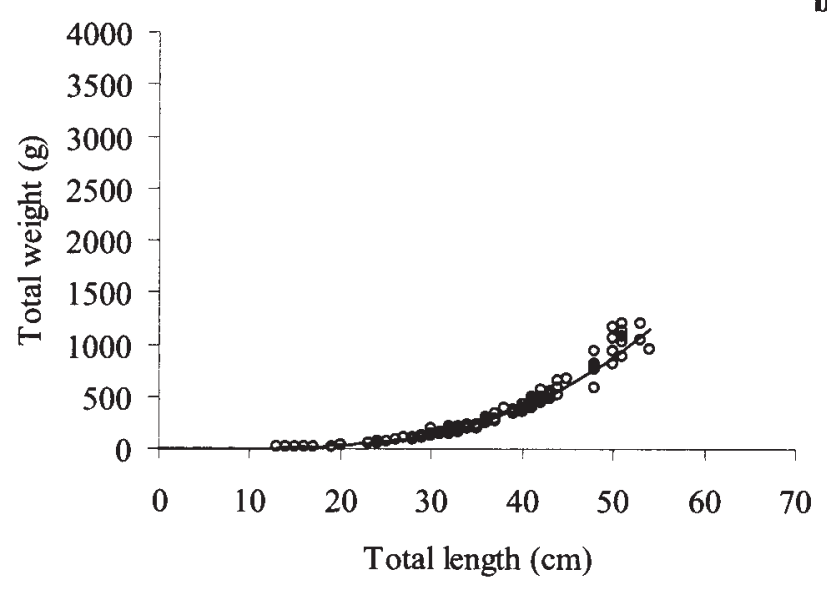

c

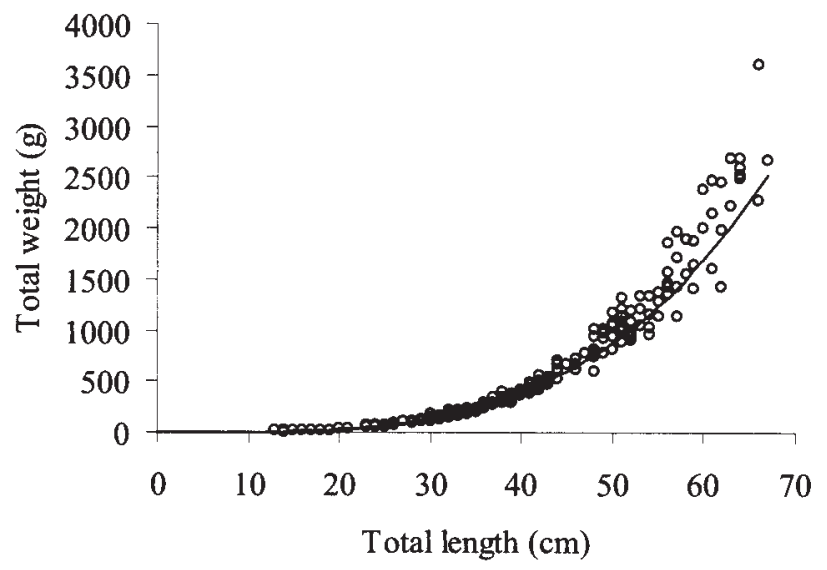

Fig. 2. Length-mass relationships for C. aceratus a. females, b. males, and c. whole population.

where $\mathrm{P}$ is the proportion of mature fish, $\mathrm{A}$ is the age in years and $\alpha$ and $\beta$ are coefficients (Ni \& Sandeman 1984). The values of the coefficients are obtained by linearizing the equation to give:

$$
\ln P /(1-P)=\alpha+\beta A
$$




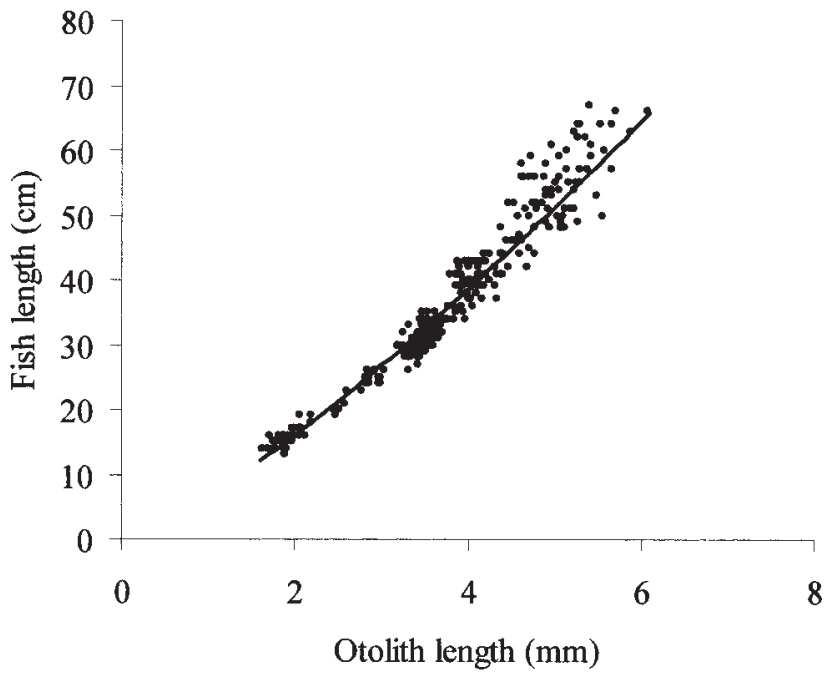

Fig. 3. Fish length-otolith length relationship of C. aceratus.

where $\alpha$ is the intercept and $\beta$ the slope. The age at first maturity (A50), defined as the age at which $50 \%$ of fish are in the mature stage, is then estimated as the negative ratio of coefficients, $-\alpha / \beta$, by substituting $P=0.5$ in the linear equation.

To evaluate growth, the von Bertalanffy growth function was fitted to the estimated age-length data using the program FISHPARM of the statistical package FSAS (Saila et al. 1988), which implements the Marquardt algorithm for non-linear least squares parameter estimation. The von Bertalanffy growth parameters $\left(\mathrm{L}_{\infty}, \mathrm{K}\right.$ and $\left.\mathrm{t}_{0}\right)$ were calculated for each sex (including specimens with indeterminate sex).

Finally, the growth performance index $(\mathrm{P}=\log \mathrm{K}+\log$ $\mathrm{W}_{\infty}$ ), which represents growth rate at the point of inflexion of the size-growth curve (Pauly 1979), was calculated to compare growth of C. aceratus with other Antarctic fish.

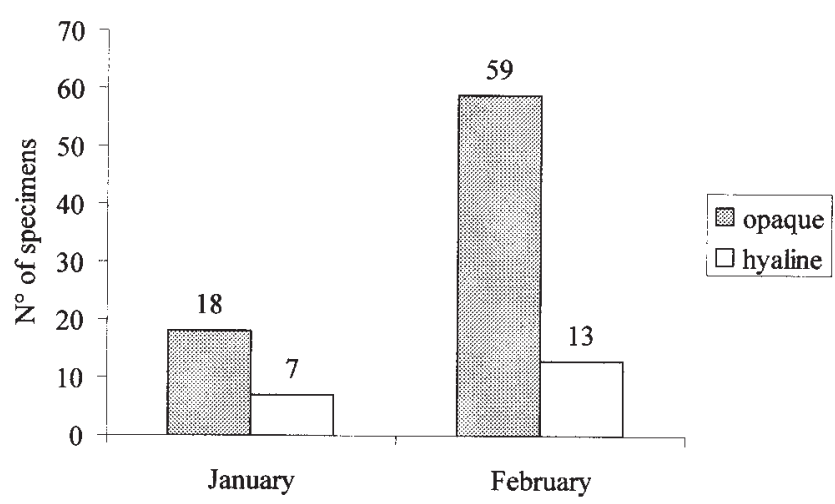

Fig. 4. Otolith margin appearance in relation to sampling month.

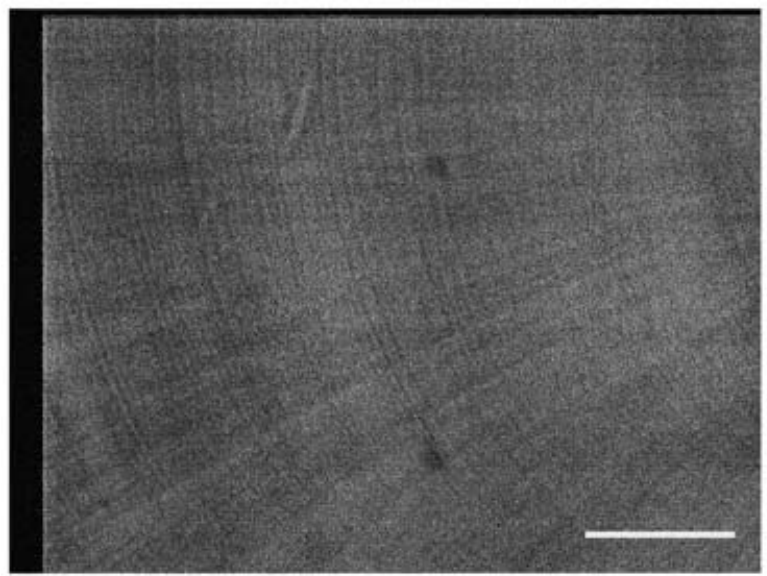

Fig. 5. Micrograph showing microincrements (daily rings) of C. aceratus sagittal otolith. Scale bar $=25 \mu \mathrm{m}, 400 \mathrm{x}$.

\section{Results}

\section{Length composition}

The length-frequency distribution of the 357 specimens sampled for this study is shown in Fig. 1. The sample included 166 females, 158 males and 33 undetermined specimens, with TL ranging from 13-67 cm. The length composition closely resembled that taken in previous studies in the same area (Skora 1988, Kock et al. 2000). Females attained larger size than males, ranging from $15-67 \mathrm{~cm}$ and from $13-54 \mathrm{~cm}$, respectively. The size range of specimens of undetermined sex was between 14-19 cm. The length-frequency distribution of the whole sample clearly showed at least three peaks (modes) at 15, 25 and $32 \mathrm{~cm}$, with little evidence of detectable modes at larger sizes.

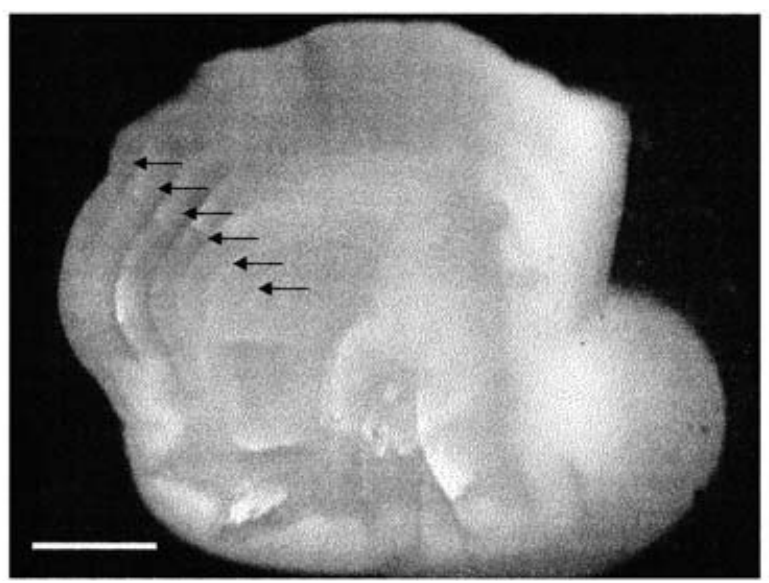

Fig. 6. Micrograph showing the annulation pattern of $C$. aceratus sagittal otolith, estimated age of $6+$ years. Arrows indicate the translucent zones. Scale bar $=500 \mu \mathrm{m}, 16 \mathrm{x}$ 
Table I. Age-length key of C. aceratus females from the South Shetland Islands.

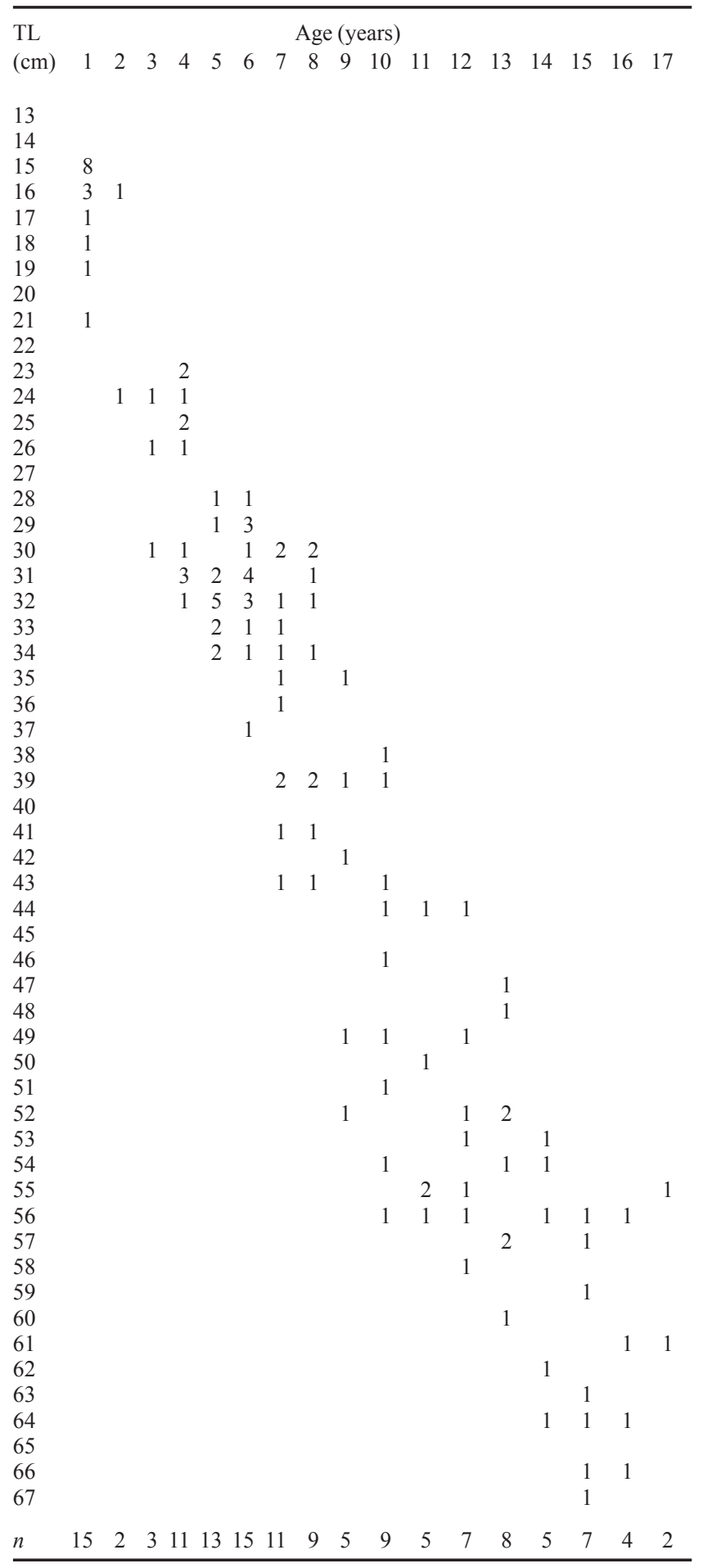

\section{Length-mass relationship}

Total mass of fish ranged from 11-3600 $\mathrm{g}$ for females and from $10-1211 \mathrm{~g}$ for males. The length-mass relationship, calculated for each sex and for the whole population, is summarized as follows:
Table II. Age-length key of C. aceratus males from the South Shetland Islands.

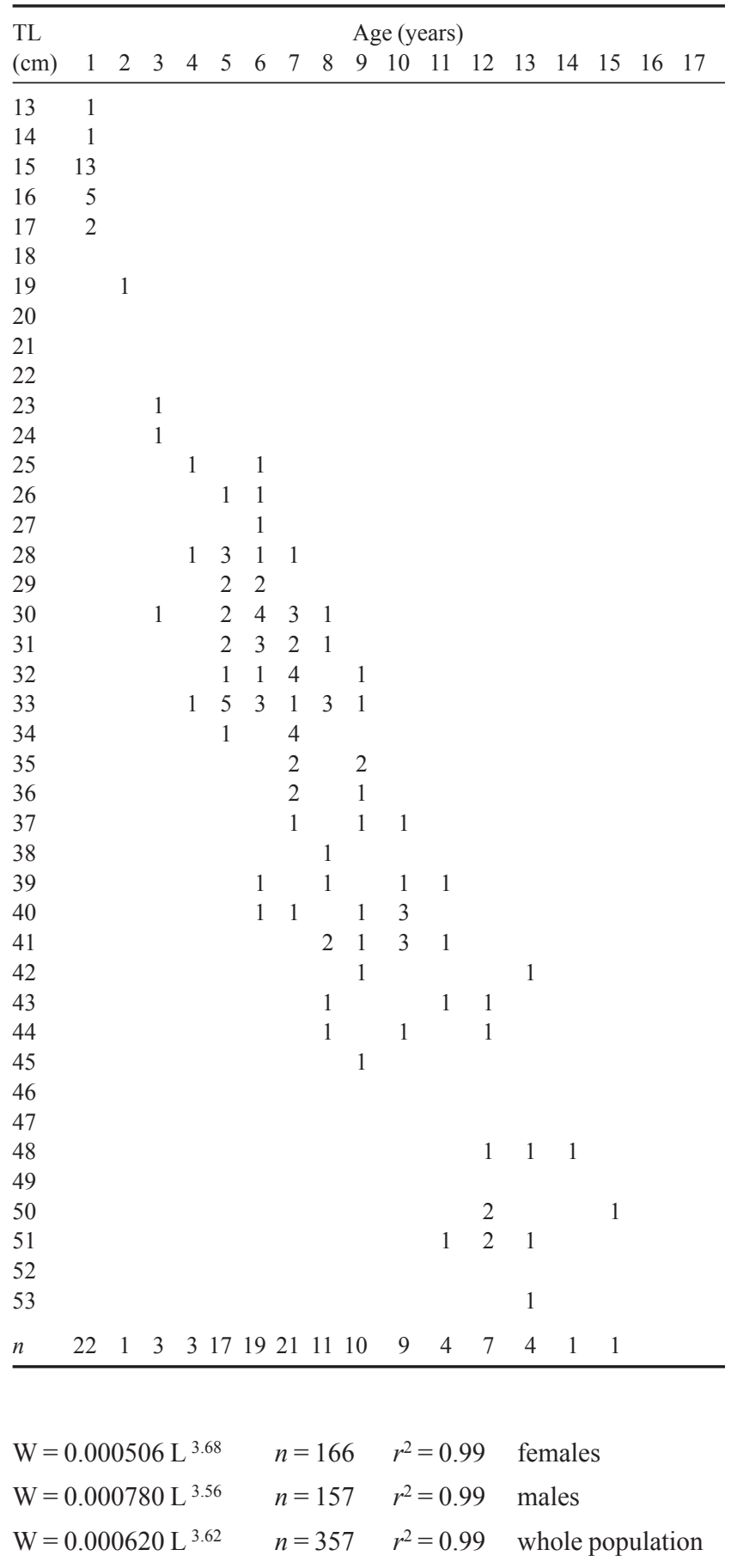

The fitted exponential curves are shown in Fig. 2. Positive allometric growth $(b>3)$ was observed in both sexes, as well as in the whole population. The allometric coefficient (b) was found to be significantly different between females and males (F-test; $F=11.29 ; P<0.01$ ).

\section{Otolith size and shape}

Diagnostic features of otoliths of $C$. aceratus are the poorly 
Table III. Estimates of the growth parameters of $C$. aceratus females and males. Ase is the asymptotic standard error and CV the coefficient of variation.

\begin{tabular}{lcccccc}
\hline & \multicolumn{3}{c}{ Females } & \multicolumn{3}{c}{ Males } \\
& Estimate & Ase & CV & Estimate & Ase & CV \\
\hline $\mathrm{L}_{\infty}$ & 79.8 & 6.82 & 0.08 & 60.0 & 4.86 & 0.08 \\
$\mathrm{~K}$ & 0.07 & 0.01 & 0.16 & 0.09 & 0.01 & 0.16 \\
$\mathrm{t}_{0}$ & -1.86 & 0.28 & 0.15 & -2.13 & 0.28 & -0.13 \\
$\mathrm{P}$ & 2.55 & & & 2.19 & & \\
\hline
\end{tabular}

defined sulcus acusticus, the thick ventral half and the comparatively thin and flat dorsal half. The most clear ontogenetic trend with age is the change of the dorsal margin, from entire to lobed to crenate (Hecht 1987, Iwami \& Kock 1990).

The maximum length of the otoliths (OL) ranged between
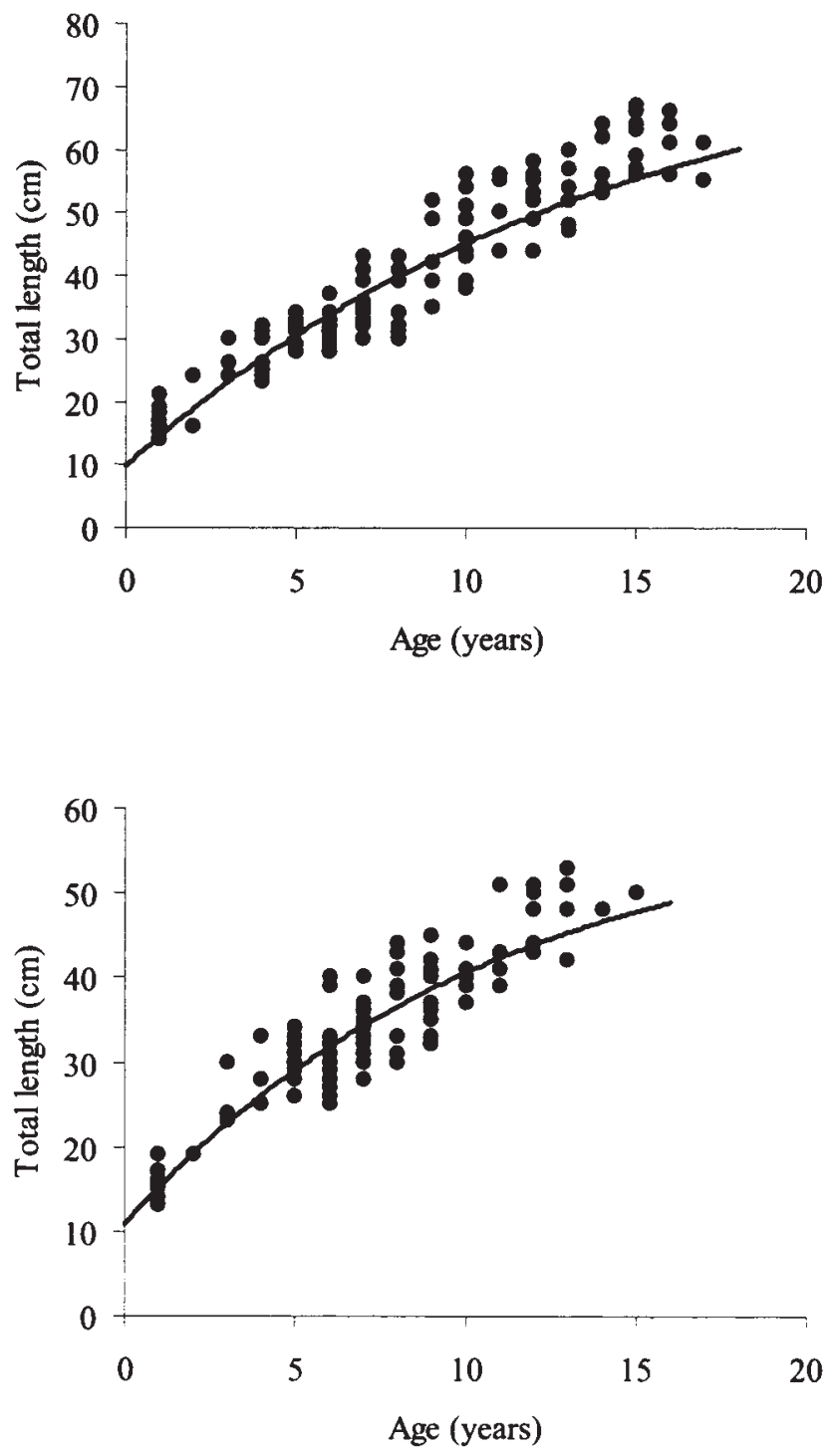

Fig. 7. Von Bertalanffy growth curves fitted to the length-age data of $C$. aceratus females (above) and males (below).
Table IV. Estimated values of fish length-at age derived from the von Bertalanffy equations. Annual growth rates are calculated by difference of fish length between two subsequent years.

\begin{tabular}{ccccc}
\hline $\begin{array}{c}\text { Estimated } \\
\text { age }\end{array}$ & \multicolumn{2}{c}{ Females } & \multicolumn{2}{c}{ Males } \\
(years) & $\begin{array}{c}\text { fish length } \\
(\mathrm{cm})\end{array}$ & $\begin{array}{c}\text { annual growth } \\
(\mathrm{cm})\end{array}$ & $\begin{array}{c}\text { fish length } \\
(\mathrm{cm})\end{array}$ & $\begin{array}{c}\text { annual growth } \\
(\mathrm{cm})\end{array}$ \\
\hline 1 & 14.5 & & 15.1 & \\
2 & 18.9 & 4.4 & 19.1 & 4 \\
3 & 23.1 & 4.2 & 22.8 & 3.7 \\
4 & 26.9 & 3.8 & 26.1 & 3.3 \\
5 & 30.5 & 3.6 & 29.1 & 3.0 \\
6 & 33.8 & 3.3 & 31.8 & 2.7 \\
7 & 37.0 & 3.2 & 34.3 & 2.5 \\
8 & 39.9 & 2.9 & 36.6 & 2.3 \\
9 & 42.6 & 2.7 & 38.7 & 2.1 \\
10 & 45.1 & 2.5 & 40.6 & 1.9 \\
11 & 47.5 & 2.4 & 42.3 & 1.7 \\
12 & 49.7 & 2.2 & 43.9 & 1.6 \\
13 & 51.7 & 2.0 & 45.3 & 1.4 \\
14 & 53.6 & 1.9 & 46.6 & 1.3 \\
15 & 55.4 & 1.8 & 47.8 & 1.2 \\
16 & 57.1 & 1.7 & & \\
17 & 58.6 & 1.5 & & \\
\hline
\end{tabular}

1.62-6.06 mm, whereas their mass (OW) was between $1.9-44.0 \mathrm{mg}$. No statistically significant difference was detected between left and right otolith mass of the same fish, suggesting a similar growth between them.

The relationship between OL and TL was slightly curvilinear (Fig. 3). The best fit of data is described by the following equation:

$$
\mathrm{TL}(\mathrm{cm})=66.7 \mathrm{OL}^{1.26} \quad n=350 \quad r^{2}=0.96
$$

Both values of the equation are very similar to those of C. aceratus reported in literature (Hecht 1987). The relationship between OW and TL was curvilinear as well. The best fit of data is summarised in the following equation:

$$
\mathrm{TL}(\mathrm{cm})=9.41 \mathrm{OW}^{0.50} \quad n=353 \quad r^{2}=0.98
$$

\section{Age validation}

The results of the analysis of the otolith margin are reported in Fig. 4. In the period of sampling (summer), the proportion of otoliths with opaque margin appeared higher than those with translucent margin in January, and it greatly increased in February. This result agrees with the general observation of a summer deposition of the opaque zone in many Antarctic fishes (North 1988), but the short period of

Table V. Mean coefficient of variation (CV) and index of average percent error (APE) within and between readers. $n$ is the number of pairwise age estimates.

\begin{tabular}{lccc}
\hline & Within reader 1 & Within reader 2 & Between readers \\
\hline CV & 5.1 & 7.5 & 9.6 \\
APE & 3.6 & 5.3 & 6.8 \\
$n$ & 294 & 77 & 75 \\
\hline
\end{tabular}



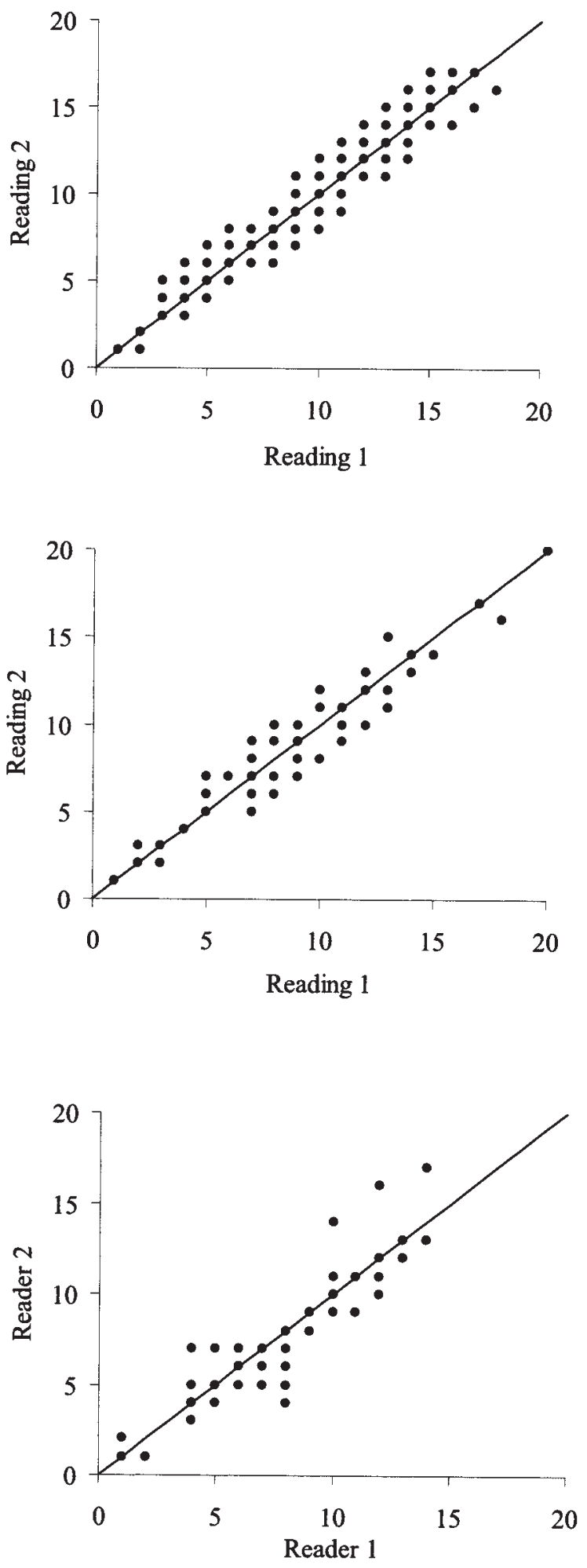

Fig. 8. Plot of pairwise age estimates a. \& b. within readers, and c. between readers. Diagonal lines represent the perfect agreement between readings/readers.

sampling did not allow the analysis to be extended further.

The ages estimated from the microincrement counts (Fig. 5) ranged between 415-458 days, consistent with their

a

b

c Downloaded from https://www.cambridge.org/core. Old Dominion University, on 02 Aug
https://www.cambridge.org/core/terms. https://doi.org/10.1017/S0954102004002044 
larger size and showed a higher growth rate than males.

\section{Age precision analysis}

Results from the comparison between age readers are summarised in Table V. To make a comparison, age readings data within and between readers were plotted along with a diagonal line representing the perfect agreement between them (Fig. 8). The precision indices APE and CV were reasonably low within and between readers, indicating that the preparation technique allowed readers to apply the criteria with reasonable consistency between readings.

\section{Age at sexual maturity}

Figure 9 shows the proportion of mature fish in relation to estimated ages, separately for females and males. By fitting the logistic curves to the data, we found females attained sexual maturity at about ten years, just one year more than males. Taking into account our age estimates, females and males of $C$. aceratus both reach sexual maturity at about $60 \%$ of their maximum age.

\section{Discussion}

Kock \& Everson (1998) have pointed out the lack of validation studies in ageing Antarctic fish. In the present paper, we attempted to critically examine the precision and accuracy of our age estimates of $C$. aceratus, where precision measures the repeatability of age interpretation and accuracy measures how close the estimated age is to the true age (Beamish \& McFarlane 1983). By comparing readings between different institutions, we were able to estimate the precision of age readings, and found consistency within and between readers that compared well with other studies on Antarctic fish. Estimates of CV and APE obtained from our data were lower than those reported for other Antarctic fish species (Ashford \& Wischniowski 1998, Morales-Nin et al. 2000, Horn 2002).

Our examination of the otolith margin indicated that the opaque zone was generally present, consistent with expected summer deposition of the opaque zone, but we were able to examine only samples collected in January and February. Samples of $C$. aceratus from throughout the year are urgently required for a full validation by marginal incremental analysis, and to provide information on the time of deposition of the translucent zone. Furthermore, one of the critical criteria in the age determination of Antarctic fish is identification of the first annulus (Morales-Nin et al. 2000), and we found for a limited sample that microincrement counts corresponded well with an age $1+$ estimated using our ageing criteria, a method already used for age validation in polar fish by Radtke \& Targett (1984). This correspondence supports our criteria identifying the first translucent zone in older specimens. However, this needs to be demonstrated for a larger sample size to be fully convincing.

The demersal fish fauna of the shelf and upper slope areas throughout the Scotia Arc has been extensively studied by trawl surveys since the mid-1960s (Kock et al. 2000). In the southernmost part of the Scotia Arc, this is true mainly for fish living around Elephant Island (Kock 1998, Kock \& Stransky 2000, Tiedtke \& Kock 1989). Recently, data on several aspects of the biology of the local fish stocks, such as species composition, reproduction and feeding habits, were reported from the lower South Shetland Islands and South Orkney Islands (Jones et al. 1998a, 1998b, 2000, 2001, Kock et al. 2000). Data on species composition in the Statistical Subarea 48.1 showed that C. aceratus is one of the most frequently encountered finfish species on the shelf area, distributed over the whole depth range sampled from 100-500 m (Kock et al. 2000, Jones et al. 2001). Around the South Shetland Islands, females and males of C. aceratus attained sexual maturity at about 48 and $38 \mathrm{~cm}$ respectively, and probably spawned between May and June (Kock et al. 2000). As occurs in other icefishes, adult specimens of $C$. aceratus fed almost exclusively on fish, whereas juveniles relied mostly on krill (Jones et al. 2001).

Yet, despite the importance of this species within this area, there is little data on age and growth of $C$. aceratus reported to date. All data reported in the literature for this species are from South Georgia (Olsen 1955, Gubsch 1980, Kompowski 1980, 1990). Based on otolith readings to determine age, Olsen (1955) reported age estimates for adult fish between 9-17 years. Such estimates were obtained from large mature specimens of $C$. aceratus; the mean length in the different year classes was $57-65 \mathrm{~cm}$ for females and 50-55 cm for males. More recently, further data on age and growth of $C$. aceratus were obtained using the first fin rays of the pelvic fin (Gubsch 1980) and whole otoliths (Kompowski 1990). In both these studies, males were aged from 1-11 years old, but females were aged from 1-12 years by Gubsch and from 1-18 years by Kompowski, although the length range of fish sampled was comparable. This discrepancy suggests that the use of pelvic fin rays in ageing $C$. aceratus may underestimate age in females relative to whole otoliths. If so, this must occur after $\mathrm{L}_{\infty}$ has been reached because the estimates of the von Bertalanffy growth parameter $K$, which represents the rate at which the fish approach their final mean size $\left(\mathrm{L}_{\infty},\right)$ and is sensitive to differences in age estimation, were very similar between the two studies, as was the derived index of growth performance (Table VI).

Our age data for $C$. aceratus agree generally with those of Kompowski (1990), showing a similar range of estimated ages, and a similar maximum age attainable by the species between the southern (lower South Shetland Islands) and northern part (South Georgia) of the Scotia Arc. Conversely, the estimates for $K$ varied considerably between the two areas. Our estimate of $K$ was less than half of that reported 
Table VI. Recent data on the age and growth of C. aceratus from the Scotia Arc region. *values calculated from published data reported below.

\begin{tabular}{|c|c|c|c|c|c|c|}
\hline \multirow{2}{*}{$\begin{array}{l}\text { Author } \\
\text { Site } \\
\text { Sex }\end{array}$} & \multicolumn{2}{|c|}{$\begin{array}{c}\text { Gubsch (1980), Kock (1981) } \\
\text { South Georgia }\end{array}$} & \multicolumn{2}{|c|}{$\begin{array}{l}\text { Kompowski (1990) } \\
\text { South Georgia }\end{array}$} & \multicolumn{2}{|c|}{$\begin{array}{l}\text { Present study } \\
\text { South Shetland Is }\end{array}$} \\
\hline & females & males & females & males & females & males \\
\hline Age (years) & $1-12$ & $1-11$ & $1-18$ & $1-11$ & $1-17$ & $1-15$ \\
\hline $\mathrm{L}_{\infty}(\mathrm{cm})$ & 76.5 & 58.0 & 75.5 & 62.0 & 79.8 & 60.0 \\
\hline $\mathrm{K}\left(\right.$ years $\left.^{-1}\right)$ & 0.17 & 0.24 & 0.17 & 0.23 & 0.07 & 0.09 \\
\hline $\mathrm{t}_{0}$ (years) & 0.474 & 0.464 & -0.011 & 0.072 & -1.86 & -2.13 \\
\hline $\mathrm{P}^{\infty}$ & $2.83^{*}$ & $2.51 *$ & $2.80 *$ & $2.64 *$ & 2.55 & 2.19 \\
\hline
\end{tabular}

by Kompowski (see Table VI), both in males and females. The index of growth performance, commonly used to compare the growth curves of different populations of the same species (Sparre et al. 1987), was consequently smaller in our study. Growth differences are a good indicator of potential genetic differences between populations, or ecological separation over much of the life history (e.g. Begg et al. 1999, Quinn \& Deriso 1999, Ashford 2001). If the differences between the two studies reflect real differences in growth rates, they support stock separation between South Georgia and the South Shetland Islands. Discrepancies in age-at-length data, perhaps as a result of different environmental conditions, for example, temperature or food availability throughout the year, can only persist if they are not homogenized by movement. However, further comparative work is needed to ensure that these differences are not explained by discrepancies in age criteria between the two studies.

Our results provide a useful starting point to evaluate how much the population of $C$. aceratus inhabiting the shelf waters of the South Shetland Islands may have been affected by the commercial exploitation carried out in the late 1980s. Although this fish was mainly caught as bycatch, the quantity taken may have been underestimated (Kock \& Stransky 2000). However, the length frequency distribution of $C$. aceratus reported in this study was similar to that previously reported from the South Shetland area (Kock et al. 1985, Skora 1988, Kock 1998). Moreover, our results are not obviously consistent with the decline in the maximum age of the population that is predictable from a substantial increase in mortality. However, as larger fish were sampled more intensely in our study to ensure that the full age range was represented, and there are no age data from earlier surveys, this conclusion must be regarded with caution until age data is available for $C$. aceratus from the earlier surveys to allow a better comparison. In any case, the slow growth rate and longevity of $C$. aceratus reported here, as well as the strong annual variation of its recruitment strength observed at Elephant Island (Skora 1988), would suggest that any renewal of fishing activity in the area should be treated with caution, and the effect of increased mortality on the stock be monitored carefully.

\section{Acknowledgements}

The authors are very much indebted to K.-H Kock, C.D. Jones, G. von Bertouch, D.F. Doolittle, L. Pschenichnov, R. Riehl, T. Romeo, S. Schöling and L. Zane for their invaluable work carried out during the Polarstern cruise. We would like also to thank the crew of the RV Polastern for their support in the sampling activities. This study was supported by the PNRA (Italian National Antarctic Research Program). We thank the referees, Drs J.T. Eastman $\&$ I. Everson, for their helpful suggestions.

\section{References}

ASHFORD, J.R. 2001. In support of a rationally managed fishery: age and growth in Patagonian toothfish (Dissostichus eleginoides). PhD thesis, Old Dominion University, Virginia. [unpublished].

AsHFORD, J.R. 2002. First annual report of the CCAMLR Otolith Network. SC-CAMLR-WG-FSA 02/51.

AsHFORD, J.R. \& WisChNIOWSKI, S. 1998. Criteria for aging the otoliths of Dissostichus eleginoides from South Georgia (Subarea 48.3) and an analysis of aging precision. SC-CAMLR-WG-FSA 98/52.

BEAMish, R.J. \& Fournier, D.A. 1981. A method of comparing the precision of a set of age determinations. Canadian Journal of Fisheries and Aquatic Sciences, 38, 982-983.

BEAmish, R.J. \& McFARLANe, G.A. 1983. Validation of age determination estimates: the forgotten requirement. Transactions of American Fisheries Society, 112, 735-743.

BegG, G.A., Hare, J.A. \& Sheehan, D.D. 1999. The role of life history parameters as indicators of stock structure. Fisheries Research, 43, $141-163$

ChANG, W.Y.B. 1982. A statistical method for evaluating the reproducibility of age determination. Canadian Journal of Fisheries and Aquatic Sciences, 39, 1208-1210.

Coggan, R., Skóra, K., Murray, A. \& White, M. 1990. A comparison between age determinations of the Antarctic fish Notothenia gibberifrons Lönnberg using scales and otoliths. Cybium, 14, 43-55.

Everson, I. 1977. The living resources of the Southern Ocean. GLO/SO/77/1. Rome: FAO/UN Development Programme, 156 pp.

EVERSON, I. 1980. Antarctic fish age determination methods. BIOMASS handbook, 8, $24 \mathrm{pp}$.

Everson, I., Bendall, B. \& Murray, A. 1999. Otolith and body size relationships in the mackerel icefish (Champsocephalus gunnari). CCAMLR Science, 6, 117-123.

GEFFEN, A.J. 1992. Validation of otolith increment deposition rate. In Stevenson, D.K. \& Campana, S.E., eds. Otolith microstructure examination and analysis. Canadian Special Publication of Fisheries and Aquatic Sciences, 117, 101-113. 
GuBsCH, G. 1980. Untersuchungen zur Alterbestimmung und zum Wachstum beim Eisfisch Chaenocephalus aceratus (Lönnberg). Fischerei-Forschung, 18, 7-10.

Hecht, T. 1987. A guide to the otoliths of Southern Ocean fishes. South African Journal of Antarctic Research, 17, 1-87.

Horn, P. 2002. Age and growth of Patagonian toothfish (Dissostichus eleginoides) and Antarctic toothfish (D. mawsoni) in waters from the New Zealand subantarctic to the Ross Sea, Antarctica. Fisheries Research, 56, 275-287.

Iwami, T. \& Kock, K.H. 1990. Channichthyidae. In Gon, O. \& Heemstra, P.C., eds. Fishes of the Southern Ocean. Grahamstown: J.L.B. Smith Institute of Ichthyology, 381-399.

Jones, C.D., Kock, K.H. \& Balguerias, E. 2000. Changes in biomass of eight species of finfish around the South Orkney Islands (Subarea 48.2) from three bottom trawl surveys. CCAMLR Science, 7, 53-74.

Jones, C.D., Kock, K.H. \& Wilhelms, S. 1998a. Standing stock biomass of eight species of finfish around Elephant Island and the lower South Shetland Islands (Subarea 48.1) from the 1998 US AMLR bottom trawl survey. SC-CCAMLR-WG-FSA-98/17.

Jones, C.D., Kock, K.H. \& Wilhelms, S. 1998b. Results from the 1998 bottom trawl survey of Elephant Island and the lower South Shetland Islands (Subarea 48.1). SC-CCAMLR-WG-FSA-98/15.

Jones, C.D., Kock, K.H., Ramm, D., Ashford, J., Wilhelms, S., NeAR, T., Gong, N. \& Flores, H. 2001. Results and standing stock biomass estimates of finfish from the 2001 US AMLR bottom trawl survey of the South Shetland Islands (Subarea 48.1). SC-CCAMLR-WG-FSA-01/33rev 1.

KeLlermann, A. 1989. Identification key and catalogue of larval Antarctic fishes. BIOMASS Science Series, No. 10, 136 pp.

Kock, K.H. 1981. Fischereibiologische Untersuchungen an drei antarktischen Fischarten: Champsocephalus gunnari (Lönnberg, 1905), Chaenocephalus aceratus (Lönnberg, 1906) und Pseudochaenichthys georgianus Norman, 1937 (Notothenioidei, Channichthyidae). Mitteilungen aus dem Institut für Seefischerei Hamburg, 32, 1-226.

Kock, K.H. 1990. Results of the CCAMLR Antarctic fish otoliths/scales/bones exchange system. SC-CCAMLR-WG-FSA$V I I I / B G / 46$.

Kock, K.H. 1992. Antarctic fish and fisheries. Cambridge: Cambridge University Press, $359 \mathrm{pp}$.

Kock, K.H. 1998. Changes in the fish biomass around Elephant Island (Subarea 48.1) from 1976 to 1996. CCAMLR Science, 5, 165-189.

Kock, K.H. \& Everson, I. 1998. Age, growth and maximum size of Antarctic notothenioid fish revisited. In Di Prisco, G., Pisano, E. \& Clarke A., eds. Fishes of Antarctica: a biological overview. Milan: Springer, 29-40.

Kock, K.-H. \& Stransky, C. 2000. The composition of the coastal fish fauna around Elephant Island (South Shetland Islands, Antarctica). Polar Biology, 23, 825-832.

Kock, K.H., Duhamel, G. \& Hureau, J.C. 1985. Biology and status of exploited Antarctic fish stocks, a review. BIOMASS Scientific Series, 6 , $1-143$.

Kock, K.-H., Jones, C.D. \& WiLHELMS, S. 2000. Biological characteristics of Antarctic fish stocks in the southern Scotia Arc region. CCAMLR Science, 7, 1-41.
Kompowski, A. 1980. Studies on juvenile Chaenocephalus aceratus (Lönnberg, 1906) (Pisces, Chaenichthyidae) from off South Georgia. Acta Ichthyologica et Piscatoria, 10, 45-53.

Kompowski, A. 1990. Biological characteristics of Scotia Sea icefish Chaenocephalus aceratus (Lönnberg, 1906) from the South Georgia area. Report of the Sea Fisheries Institute Gdynia, 22, 49-71.

La Mesa, M. \& VaCCHI, M. 2001. Review: Age and growth of highAntarctic notothenioid fish. Antarctic Science, 13, 227-235.

Morales-Nin, B., Moranta, J. \& Balguerias, E. 2000. Growth and age validation in high-Antarctic fish. Polar Biology, 23, 626-634.

NeILSON, J.D. 1992. Sources of error in otolith microstructure examination. In Stevenson, D.K. \& Campana, S.E., eds. Otolith microstructure examination and analysis. Canadian Special Publication of Fisheries and Aquatic Sciences, 117, 115-126.

NI, I.H. \& SANDEMAN, E.J. 1984. Size at maturity for Northwest Atlantic redfishes (Sebastes). Canadian Journal of Fisheries and Aquatic Sciences, 41, 1753-1762.

NORTH, A.W. 1988. Age of Antarctic fish: validation of the timing of annuli formation in otoliths and scales. Cybium, 12, 107-114.

North, A.W., White, M.G. \& Burchett, M.S. 1980. Age determination of Antarctic fish. Cybium, 8, 7-11.

Olsen, S. 1955. A contribution to the systematics and biology of Chaenichthyid fishes from South Georgia. Nytt Magasin of Zoology, 3, 79-93.

PAuLY, D. 1979. Gill size and temperature as governing factors in fish growth: a generalization of the von Bertalanffy' growth formula. Berichte aus dem Institut für Meerskunde an der Christian-AlbrechtsUniversität Kiel, 63, 1-156.

Quinn, T.J. \& Deriso, R.B. 1999. Quantitative Fish Dynamics. Oxford: Oxford University Press, $560 \mathrm{pp}$.

RADTKE, R.L. \& TARGETT, T.E. 1984. Rhythmic structural and chemical patterns in otoliths of the Antarctic fish Notothenia larseni: their application to age determination. Polar Biology, 3, 203-210.

Saila, S., Recksiek, C. \& Prager, M. 1988. Basic fishery science programs. Amsterdam: Elsevier, $230 \mathrm{pp}$.

SKÓRA, K.E. 1988. Benthic fishes of the Elephant Island shelf (BIOMASS III, October-November 1986 and February 1987). Polish Polar Research, 9, 385-398.

SLÓSARCZYK, W. 1987. Contribution to the early life history of Channichthyidae from the Bransfield Strait and South Georgia (Antarctica). In Kullander, S.O. \& Fernholm, B., eds. Proceedings of the Fifth Congress of European Ichthyological Society. Stockholm: Swedish Museum of Natural History, 427-433.

SOKAL, R.R. \& RoHLF, F.J. 1969. Biometry. The principle and practice of statistics in biological research. San Francisco, CA: W.H. Freeman, $776 \mathrm{pp}$.

SparRe, P., Ursin, E. \& Venema, S.C. 1987. Introduction to tropical fish stock assessment. Part 1 - Manual. FAO Fisheries Technical Papers, 306/1, 1-376.

TiEdTKe, J.E. \& Kock, K.H. 1989. Structure and composition of the demersal fish fauna around Elephant Island. Archive of Fishery and Marine Research, 39, 143-169.

White, M.G. 1991. Age determination in Antarctic fish. In DI PRISCO, G., Maresca, B. \& TotA, B., eds. Biology of Antarctic fish. Berlin: Springer, $87-100$. 